\title{
¡Defendamos Dichato! Bienes comunes y conflicto territorial en los espacios litorales chilenos ${ }^{1}$
}

\author{
Pablo Camus², Rodrigo Hidalgo ${ }^{3}$, Leonel Pérez ${ }^{4}$ \\ y Enrique Muñoz ${ }^{5}$
}

\begin{abstract}
RESUMEN
El Código Civil de la República de Chile estableció que los pescadores podían hacer uso de las playas del mar para sus labores de pesca, definiendo de este modo un espacio litoral de uso común independiente de los propietarios aledaños que pronto se transformaría en un territorio de conflicto que se incrementaría en la medida que distintas actividades económicas se fueron superponiendo en estos espacios comunes. En este artículo presentamos algunos ejemplos históricos que reflejan como los pescadores utilizaron este derecho en defensa de sus intereses relevando, especialmente, el caso del borde costero de Dichato que poco antes de mediados del siglo XX fue el escenario de un conflicto que involucró al Estado, los propietarios, los pescadores y los veraneantes.
\end{abstract}

Palabras claves: Bienes comunes, espacios litorales, pescadores, Dichato.

\begin{abstract}
The Civil Code of the Republic of Chile established that fishermen could make use of the sea beaches for their fishing activities, thereby defining a coastline space of independent common use for the neighboring owners, who would soon become a territory of conflict that would increase to the extent that different economic activities were superimposed on these common spaces. This paper presents some historical examples that reflect how fishermen used this right to defend their interests. Special atention is given to the case of the coastal edge of Dichato, shortly before it were the scene of a conflict involving the State, owners, fishermen and vacationers in the mid-twentieth century.
\end{abstract}

Key words: common property, artisanal fishing, coastal areas, Dichato.

Proyecto FONDECYT No 1150331, La "tragedia de los comunes" en los mares y litorales de Chile central. Hacia una historia de las relaciones humanas con los ambientes y ecosistemas marinos y costaneros. s. XIX Y XX. Artículo recibido el 10 de octubre de 2016, aceptado el 4 de abril de 2017 y corregido el 5 de junio de 2017

Center of Applied Ecology \& Sustainability (CAPES) / Instituto de Historia, Pontificia Universidad Católica de Chile (Chile).

E-mail: pcamusg@uc.cl

Instituto de Geografía, Pontificia Universidad Católica de Chile (Chile). E-mail: rhidalgd@uc.cl

Departamento de Urbanismo, Universidad de Concepción (Chile). E-mail: leperez@udec.cl

5 Licenciado en Historia, Pontificia Universidad Católica de Chile (Chile). E-mail: evmunoz@uc.cl 
En Chile la mayor parte de la historiografía se ha ocupado del Valle Central y de los espacios geográficos interiores, por lo que prácticamente desconocemos por completo la historia de la ocupación y del poblamiento de los espacios litorales, de la formación de colonias de pescadores y de sus formas de vida ligadas al mar. Tampoco hay una historia económica y menos ambiental de la explotación y aprovechamiento de los recursos marítimos y litorales. Poco se sabe acerca del comercio, del cabotaje, la pesca o de la existencia de astilleros y otras actividades económicas relacionadas con el mar y los espacios costaneros. Revisando la bibliografía marítima, se ve que de la caza de ballenas (Cartes, 2009; Berrios, 2011; Hernandez, 2005; Nicholls, 2010) es un tema trabajado, e.g., en la región del Bíobío, se ha relevado a caleta Chome como el único asentamiento creado por la industria ballenera que se mantiene hasta la actualidad debido a que fue la industria de mayor duración y de mayor influencia regional (Rosenberg, 2011). Destaca también la historia de la marina mercante iniciada por Uribe (1904). Por su parte, Veliz planteaba que le resultaba extraño que "una nación con un litoral tan extenso, un territorio ${ }^{6}$ interior tan limitado e inaccesible y una economía tradicionalmente orientada hacia el exterior no haya desarrollado una marina mercante de importancia" (1961: 15). Más alineado con la historia épica Alvarez de la Rivera destaca "la escasa visión marítima de la gran mayoría de los políticos y gobernantes nacionales" (2006: 263).

Otra perspectiva ha sido el estudio de la marina de guerra y de los acontecimientos y catástrofes marítimas y navales. Vázquez de Acuña (2004) publicó una monumental obra que estudia la historia naval de nuestro mar, pero centrada en forma exclusiva en el período colonial. Concuerda con el diagnostico de que "el mar ha sido un elemento que curiosamente no penetró en la mentalidad nacional por habérselo considerado más una barrera, defensa natural, vía difícil, que medio de contacto o expansión" (Vázquez de Acuña, 2004: 547). En la misma línea es "El poder Naval Chileno", editado por la Armada, en función de sus intereses políticos marítimos, evaluando a Chile como el país naturalmente más marítimo del mundo (Armada de Chile, 1985). Bascuñán et al. (2011) estudiaron los naufragios en las costas de Chile relacionando estos acontecimientos específicos con la historia de tierra firme, con el objetivo de entregar una mirada diferente situándose en latitudes que le permiten ver las costas de Chile desde el océano. Vargas (2000) se centra en algunos siniestros marítimos acaecidos en el siglo XX, mientras que hace ya varias décadas Wardle (1940) escribió una historia del mar sobre las hazañas marítimas y el significado del inicio de la navegación a vapor en el Océano Pacífico.

A pesar de estos aportes, no se ha reflexionado todavía en torno a los procesos y conflictos territoriales, políticos, económicos y sociales que han operado en los espacios litorales y marítimos nacionales que han terminado por originar una serie de mecanismos de supervivencia y adapta-

\footnotetext{
Si bien el concepto de territorio es uno básico de la geografía consideramos es que es necesario replantearnos que entendemos por él, tal como dice Elden (2010: 238): "For a long time territory was the dead, the fixed, the immobile, the under-examined. At least, so the books under review here argue in different ways, within political science, political philosophy and international relations. Political geography has, of course, long seen territory as one of its key concepts. Yet if political geographers have offered a range of excellent, detailed accounts of territories, there has been less examination of 'territory'. As I and others have suggested, territory is all too often seen by geographers as a relatively straight-forward concept, something that can be understood as a bounded space under the control of a group, perhaps a state, or an outcome of territoriality". Esta problematización del concepto a la luz de la teoría política es lo que hace Kolers (2009: 4) "Territoriality is in the first instance a strategy of bounding and controlling, and thereby making, geographic places. A territory is a geographic place that is bounded and controlled in part through geographical means such as the establishment of physical boundaries or other means of demarcation. To control a territory is to be able to make and enforce what the geographer Robert Sack calls the in/out of place rules, and the flows of people across the border and within the place itself."
} 
ción cultural especialmente de los pescadores tradicionales o artesanales, quienes son prácticamente desconocidos por la historiografía. Las "historias del mar", entonces, se han limitado a narrar sucesos épicos; heroicos o catastróficos, y desarrollos institucionales y analizar problemas geopolíticos relacionados con el poder naval.

Esta perspectiva más alineada con la épica y el heroísmo no se ha impuesto sólo en Chile. Bolster (2006) solicitó a los historiadores prestar más atención al estudio de las interacciones entre los seres humanos con los ecosistemas marinos. Los litorales y los océanos se habían convertido en la última frontera de los historiadores ambientales pues, a juicio de él, la historia de las interrelaciones entre las acciones humanas y los procesos del medio marino permanecía aún, en gran parte, sin investigar. En esta línea el 2013 Environmental History Review publicó un especial dedicado a la historia de los ecosistemas marinos Marine Forum. Destacamos a Payne (2013), quien planteó que los historiadores habían puesto en relieve el papel que jugaban los pescadores, tanto en sus comunidades como en la conservación de los recursos naturales, administrándolos de cerca y limitando al mismo tiempo también el impacto del capitalismo industrial con el objetivo de resguardar sus modos de vida. Estos estudios habrían creado, según Payne, la falsa imagen de una pesca artesanal que ha buscado la independencia de las fuerzas del mercado. Su artículo ilustra cómo los pescadores podían ser tanto productivistas como conservacionistas. Sus campañas - indica - estaban dirigidas menos hacia la producción limitada que hacia el control local de esa producción. En tanto uno de los problemas transversales de las interacciones humanas con los ecosistemas marinos ha sido la tensión existente por el control de los recursos naturales y bienes comunes entre las comunidades de pescadores y su gestión colectiva de los bienes y riquezas, y la mirada del mar más productivista generada a raíz de las nuevas tecnologías y modos de producción aplicadas a la pesca lo que impulsó la privatización y la industrialización de la extracción de los recursos marítimos.

Esta tensa relación que se ha estudiado desde la economía (Ostrom, 1990), la geografía (SeviIla-Buitrago, 2012), la antropología marina (Alegret, 1989) y, también, más recientemente, desde la historia ambiental (Smout, 2011), se ha centrado en el marco epistemológico del estudio y análisis de la polémica de los denominados "bienes comunes", que adquieren especial importancia en el medio marino a partir de la segunda mitad del siglo XX cuando biólogos y ecólogos tomaron conciencia de que los recursos pesqueros no eran inagotables. Planteada en 1833 por el economista británico William Forster Lloyd, la idea de que la "propiedad de todos es propiedad de nadie" fue retomada a mediados del siglo XX por Gordon (1954) y Scott (1955), quienes, casi de forma concomitante, postularon que sólo cuando se es propietario de un bien se produce un verdadero incentivo para conservar, eficientemente, los recursos que se le asocian, proponiendo, en este sentido, un régimen de la propiedad privada, o bien, de propiedad del Estado de los denominados recursos comunes.

Como es sabido más influyente fue el artículo de Hardin (1995) originalmente publicado en 1968 por Science, quien planteó en su trabajo el peligro que el uso común de un recurso natural tenía para su propia conservación. Los recursos marinos calzan como modelo ejemplar pues su régimen de propiedad, difícil contención y cercamiento inevitablemente concluiría con el colapso de los ecosistemas. "La ruina es el destino hacia el cual corren todos los hombres, cada uno buscando su mejor provecho en un mundo que cree en la libertad de los recursos comunes. La libertad de los recursos comunes resulta la ruina para todos" (Hardin, 1995: 41). Pero lo que esta 
supuesta sensatez del "argumento pasa por alto es que los commoners mismos no carecían de sentido común" (Thompson, 1995: 127).

A pesar de las múltiples críticas, ver infra, la tesis de Hardin fue hipostasiada a status de ley científica por la economía y los estudios ambientales lo que sirvió para justificar "científicamente" un ambientalismo neoliberal los últimos 30 años que buscaría soluciones a los problemas ambientales mediante mecanismos de mercado que logren conciliar el crecimiento de la producción con el medio ambiente y la conservación, lo cual se ha expresado políticamente, e.g., en los créditos de emisión transables o en la progresiva privatización de los océanos (Rodriguez, 2011). Conceptos como bienes comunes, sobrecapacidad, sobreexplotación y sobrepesca serían claves dentro del abrumador predominio de los enfoques neoliberales en relación con la gestión de los ecosistemas y de los recursos marinos (Barca, 2007; March, 2013; Mansfield 2004a; Mansfield, 2004b; Mansfield, 2008; McCarthy \& Prudham, 2004). Pero "los conceptos en la medida que presiden la toma de decisiones estratégicas en momentos de crisis o de pre-crisis, necesitan ser reconstituidos históricamente" (Salazar, 2012: 111). Por lo tanto, urge hacer una revisión histórico-critica de tales conceptos medioambientales de corte neoliberal sobre todo si consideramos que desde 1990 ha desaparecido un 10\% de naturaleza salvaje del planeta, equivalente aproximadamente a la superficie a la India (Thiberge, 2016).

En este sentido, en el último tiempo han surgido importantes críticas a las tesis de Hardin y podemos renombrarla como "la tragedia de los cercamientos" (González de Molina, 2000: 20). La crítica central a las tesis de Hardin es dar cuenta de que la propiedad común no es lo mismo que la inexistencia de propiedad (Feeny et al., 1990). Los hechos están en contra de Hardin ya que como demuestran las investigaciones empíricas a lo largo del globo las comunidades han constituido una amplia gama de instituciones y normas para regular y limitar el uso, además de prever la sobreexplotación (Durrenberger \& Pálsson, 1987). La gestión de los bienes comunes debía ser entendida, entonces, más bien en torno a la dinámica de los conflictos entre diferentes grupos sociales situados en momentos históricos concretos (Aguilera, 1991; Gascón, 1996; March, 2013; McCay \& Jentoft, 1998).

Harvey (2004) caracteriza de manera precisa la importancia de la privatización de los bienes comunales dentro de lógica de la acumulación originaria del capital estudiado por Marx (2010) en el célebre capítulo XXIV de El capital. "La mercantilización y privatización de la tierra y la expulsión forzosa de las poblaciones campesinas; la conversión de diversas formas de derechos de propiedad-común, colectiva, estatal, etc.- en derechos de propiedad exclusivos; la supresión del derecho a los bienes comunes" (Harvey, 2004: 112). Pascual Fernández (2008) indica que la vida silvestre y los bienes comunes vienen privatizándose constantemente desde el siglo XVI, cuando los grandes señores ingleses iniciaron el cercamiento de las tierras comunes. La acumulación interminable del capital "produces periodic crises within the territorial logic because of the need to create a parallel accumulation of political/military power" (Harvey, 2003: 183). En el caso de los derechos de propiedad del mar se ve como la regulación estatal, durante el XIX y el XX, ha estado en función de la acumulación internacional del capital, especialmente aquella de corto plazo, con una preocupación secundaria de las poblaciones y ecosistemas locales (Breton \& Chares, 1981), un caso en Latinoamérica es de Baja California, México (Young, 2001)7.

En este sentido las políticas públicas en torno al territorio tienen una dimensión geopolítica ineludible tal como desarrolla Chomsky (2016) al abordar los espacios comunes y su proceso de privatización. Chomsky entiende los espacios comunes como un "legado compartido por 
En este marco de análisis, en este artículo plantea las relaciones que se establecieron entre los propietarios costaneros, el Estado y los pescadores en las costas y playas de la zona central de Chile en torno a la propiedad común de la franja litoral o costanera, a partir de la aprobación del Código Civil de la República de Chile que estableció el derecho de ocupación de pesca del borde costero $^{8}$ y del mar. Nos referiremos en profundidad a un conflicto suscitado antes de promediar el siglo XX en la localidad costanera de Dichato.

\title{
La "tragedia de los comunes" en las costas de Chile durante los siglo XIX y XX
}

La legislación republicana que reguló la relación entre los pescadores, los propietarios agrícolas y el Estado fue el Código Civil de la República de Chile de 1856, el cual indicaba en su artículo 612 que

\begin{abstract}
"los pescadores podrán hacer de las playas del mar el uso necesario para la pesca, construyendo cabañas, sacando a tierra sus barcas y utensilios y el producto de la pesca, secando sus redes, etc.; guardándose empero de hacer uso alguno de los edificios o construcciones que allí hubiere, sin permiso de sus dueños, o de embarazar el uso legítimo de los demás pescadores. Art. 613. Podrán también para los expresados menesteres hacer uso de las tierras contiguas hasta la distancia de ocho metros de la playa; pero no tocarán a los edificios o construcciones que dentro de esa distancia hubiere, ni atravesarán las cercas, ni se introducirán en las arboledas, plantíos o siembras. Art. 614. Los dueños de las tierras contiguas a la playa no podrán poner cercas, ni hacer edificios, construcciones o cultivos dentro de los dichos ocho metros, sino dejando de trecho en trecho suficientes y cómodos espacios para los menesteres de la pesca. En caso contrario ocurrirán los pescadores a las autoridades locales para que pongan el conveniente remedio" (República de Chile, 1856).
\end{abstract}

Evidentemente, esta convivencia regulada no constituyó impedimento para que surgieran conflictos entre los ocupantes de los bienes comunes de las costas y playas de la zona central de Chile y los propietarios colindantes. Federico Albert denunció que hacia fines del siglo XIX y principios del XX, nadie quería tener pescadores en las playas y zonas costaneras a sus propiedades. Los dueños de los fundos litorales, muchas veces ayudados por la policía local, "que por regla general secunda al poderoso" (Albert, 2012: 283), cercaban e interrumpían el tráfico de pasajeros y bienes, y desalojaban a los pescadores de sus viviendas, "quemándolas en muchos casos" (Albert, 2012: 283).

la comunidad, cuidado de forma conjunta para uso propio y de generaciones futuras, y protegido de la privatización y de la transferencia a manos de poderes privados a fin de que genera riqueza y no sirva a las necesidades". Por su parte Harvey (2001: 326-327) muestra "the significance and evolution of state functions (local, regional, national, and supranational), uneven geographical development, interregional inequalities, imperialism, the progress and forms of urbanisation and the like. Only in this way can we understand how territorial configurations and class alliances are shaped and reshaped, how territories lose or gain in economic, political, and military power, the external limits on internal state autonomy (including the transition to socialism), or how state power, once constituted, can itself become a barrier to the unencumbered accumulation of capital, or a strategic centre from which class struggle or interimperialist struggles can be waged".

3 Para una aproximación detallada del concepto de espacios litorales y borde costero véase Haslett (2009: 1): “The coast represents the crossroads between the oceans, land and atmosphere, and all three contribute to the physical and ecological evolution of coastlines. Coasts are dynamic systems, with identifiable inputs and outputs of energy and material." 
De acuerdo con Albert (2012), en el pasado había sido frecuente encontrar colonias de pescadores profesionales diseminadas en la costa y en ciertos puntos como Matanza, San Vicente, Talcahuano, Valparaíso, San Antonio, Constitución, Quintero, Maitencillo, Zapallar, Papudo, Pichidangui, Tongoy. Con el transcurso del tiempo, atropellando el Código Civil, los propietarios que colindaban con la franja litoral habían arrasado con estas colonias. A su juicio, la inexplicable mala voluntad de los dueños de fundo impedía la conformación de colonias de pescadores. No obstante, mediante la acción del Servicio de Agua y Bosques que dirigía había sido "posible obligar a esas policías que amparen los derechos de los pescadores contra los usurpadores de terrenos fiscales" (Albert, 2012: 283).

En este sentido, él mismo había realizado numerosas diligencias y conversado con varios parlamentarios con el objetivo de aprobar una legislación que permitiese el arraigo de las colonias de pescadores en el litoral con el objetivo de desarrollar esta actividad y suministrar alimentos a la población (Albert, 2012). No obstante, muy avanzado el siglo XX, un abogado del propietario de la hacienda Los Molles nos ha revelado un episodio entre su dueño y el presidente Jorge Alessandri, quien le habría señalado que si seguía persiguiendo y hostilizando a los pescadores de Pichidanguí el mismo enviaría al ejército para proteger a los pescadores ${ }^{9}$.

Por otra parte, tras la aprobación de la ley № 1949 del 24 de junio de 1907, que estableció primas de fomento a la pesquería, incentivando la inversión de capitales, se originaron diversos concesionarios y arrendatarios de playas y litorales fiscales para el desarrollo de proyectos de explotación a gran escala quienes también se convirtieron en una competencia por los bienes comunes para los pescadores costaneros libres tanto por el uso de la franja litoral como por la explotación de los recursos del mar. Por ejemplo, la isla de Santa-María situada frente a la costa de Arauco, que fue cedida en concesión a los señores Fartón y Castillón, quienes a principios del siglo XX instalaron una verdadera factoría de pesca, atendida por 17 familias de pescadores (Revista Católica, 1913). O bien la solicitud de la Sociedad Nacional de Pesca (SONAPESCA) para arrendar los islotes Choros, Gaviotas y Damas para construir habitaciones para sus pescadores. Otro caso que hemos hallado es la solicitud en el sur del país de la "concesión en arrendamiento de los bancos de moluscos en Ancud, Maullín, Calbuco y Guaitecas e islas adyacentes"10.

Todavía en 1967, los vecinos ribereños del canal de Quihua expresaban su "malestar y alarma por haberse entregado a la Sociedad Beneficiaria del Mar la concesión del referido canal lo que privaría a los reclamantes a seguir viviendo de la pesca y extracción de mariscos" 11 . No obstante, pese a los reclamos de los pescadores, en este caso la autoridad respondió que "en conformidad a los antecedentes que se acompañan no existen problemas con lo que indican los cincuenta y cinco firmantes"12. Más recientes son las concesiones otorgadas a las empresas salmoneras en el borde costero próximo a Puerto Montt las que han limitado efectivamente el acceso de los pescadores artesanales a las orillas de las playas, deteriorado al mismo tiempo los ecosistemas marinos litorales y sus fuentes de trabajo y alimentación (Monsalve, 2014).

\footnotetext{
Entrevista realizada a Enrique Camus, 2 de mayo, 2016

Archivo Nacional. Ministerio de Obras Públicas. Volumen 2507, 1912.

Archivo Nacional. Fondo Ministerio de Agricultura. Volumen 1752. 1967

Archivo Nacional. Fondo Ministerio de Agricultura. Volumen 1752. 1967.
} 
Otro modo de limitación al acceso a los bienes comunes litorales y marinos fueron las progresivas vedas que se impusieron a la extracción de las diversas especies marinas en peligro de extinción ${ }^{13}$ o bien el establecimiento de primas que debían pagar aquellos que fuesen sorprendidos cazando algunos tipos de ballenas, lobos, langostas, centollas, ostras, ostiones, mejillones y erizos, también mediante la prohibición de pescar con dinamita (República de Chile, 1925), fenómenos interesantes pues desmienten de algún modo la tradicional visión del pescador no industrial conservacionista.

Finalmente, otra de las formas que adquirió la disputa referida al uso y aprovechamiento de los bienes comunes ocupados por pescadores fue la construcción de obras portuarias y militares, e.g., el conflicto entre los pescadores y el Ministerio de Hacienda, encargado del manejo de los puertos, en la caleta Jaime de Valparaíso ${ }^{14}$ o bien las seiscientas familias de pescadores expropiados y despojados de sus asentamientos para formar un puerto militar en Talcahuano ${ }^{15}$, como, también, las cien familias que quedaron sin sus habitaciones en San Vicente a raíz de la construcción de obras portuarias ${ }^{16}$. Este fenómeno se repitió en la década de 1960 cuando se inició la construcción de un nuevo puerto comercial en San Vicente que obligaría a desalojar una caleta de pescadores que contaba con más de dos mil viviendas ${ }^{17}$.

\section{Cercamiento de los bienes comunes litorales y conflicto territorial: el caso de Dichato hacia 1940}

Frente a la proliferación de actividades económicas, recreativas y de materialización de obras de infraestructura que comenzaban a demandar, ocupar y cercar crecientemente los espacios litorales, compitiendo por el uso de la franja costanera con los ocupantes originarios dedicados a la pesca y la extracción de mariscos, los pescadores intentaron hacer valer los derechos de ocupación que le otorgaba el Código Civil de la República de Chile de 1856. En este contexto, paulatinamente, comenzaron a emerger mecanismos de adaptación y sobrevivencia al nuevo sistema de concesiones y pago de primas pesqueras que muchas veces les impedía ejercer libremente la pesca, utilizando como argumento su derecho a la utilización de los bienes comunes costaneros. Un ejemplo de ello son los pescadores de Pudeto quienes solicitaron al Ministerio de Hacienda restablecer en los bancos de choros concesionados "un derecho de extracción proporcional ya que la competencia favorecía muy desigualmente a los industriales"18.

Otra situación relacionada con la utilización y el control de los "bienes comunes litorales" se originó a raíz de una solicitud efectuada por el gobernador marítimo de Talcahuano al presidente de la República para habilitar la caleta San Pedro, en la boca del Biobío, donde existía una colonia de pescadores que le había causado una "impresión de lo más favorable por tratarse de "gente sobria y humilde sin tener los vicios de los pescadores de los puertos" y por lo tanto estimaba que eran "acreedores de la protección del Estado"... habilitándose así la caleta de San Pedro para

\footnotetext{
Archivo Nacional. Fondo Ministerio de Obras Públicas. Volumen 2929, 1919.

Archivo Nacional. Fondo Ministerio de Hacienda. Volumen 4773, 1913

Archivo Nacional. Ministerio de Obras Públicas. Volumen 2507, 1912.

Archivo Nacional. Ministerio de Obras Públicas. Volumen 2507, 1912

Archivo Nacional. Fondo Ministerio de Agricultura. Volumen 1752. 1967.

Archivo Nacional. Fondo Ministerio de Hacienda. Volumen 4773, 1913.
} 
"efectos de embarque del pescado y marisco"19 y, por lo tanto, en definitiva, cobrar directamente la prima fiscal establecida por ley. A juicio de las autoridades marítimas de la época, "hoy por hoy se conforman en sacar la pesca necesaria para vivir sin grandes necesidades pero al ayudarles con la prima correspondiente aumentarían considerablemente su producción lo que haría bajar el precio en Concepción y Santiago" 20 .

Figura $\mathrm{N}^{\circ} 1$

Plano terrenos ocupados por particulares sin derechos legales bahía de Coliumo y playa Dichato

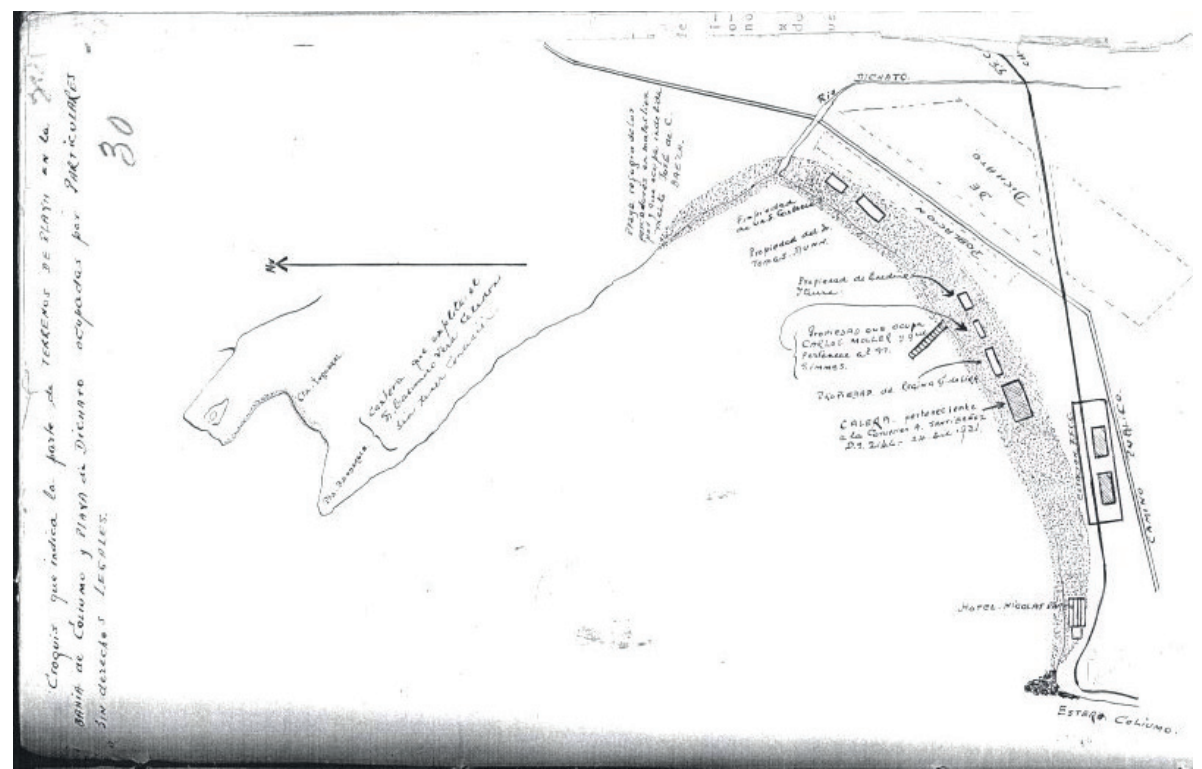

Fuente: Archivo Nacional. Ministerio de Bienes Nacionales. Volumen 3258, 1948.

Sobre la utilización de la faja costanera y los conflictos territoriales que ocasionaba definir los derechos de propiedad, tenemos antecedentes de un caso notable que enfrentó los intereses de propietarios, concesionarios, pescadores, veraneantes y del Estado como fue el caso de Dichato. En 1934 los pescadores de la localidad reclamaron ante el juez de letras de Tomé que el señor Cid Mora, propietario de los terrenos colindantes con la franja litoral, los hostigaba continuamente, inclusive incendiando sus casas.

Frente al conflicto y las demandas de los pescadores, el 19 de julio de 1934, en respuesta a un oficio enviado por la Subsecretaría de Marina, Luis Lagos, Director de la Dirección General de Pesca y Caza, expresaba la necesidad de declarar a Dichato como Caleta Pesquera, con el objetivo de "terminar con las dificultades existentes entre los pescadores que han construido sus viviendas y los concesionarios de terrenos de playas con les cobran arrendamiento". A juicio de Lagos, era

Archivo Nacional. Ministerio de Obras Públicas. Volumen 2929, 1919

20 Archivo Nacional. Ministerio de Obras Públicas. Volumen 3417, 1922. 
conveniente "arbitrar medios que permitan terminar con la situación anómala existente, con perjuicio directo del numeroso gremio de pescadores de las caletas de Coliumo y Dichato"21.

En ambas caletas, señalaba, "los pescadores eran víctimas de las exigencias de los dueños de los terrenos continuos a la playa o concesionarios de ésta, no permitiéndoles hacer uso libremente para sus faenas pesqueras de los ocho metros de la más alta marea a que tienen derecho" ver figura $N^{\circ} 1$. Para poner término a la situación consideraba que era necesario que la superioridad naval designara a un funcionario que demarcara en el terreno mismo los terrenos de playas fiscales indicando en forma precisa los ocho metros "a que tienen derecho los pescadores según la Ley de Pesca y el Código Civil" y "las concesiones de playa vigentes y caducadas con indicación de sus deslindes, superficie y fecha de terminación". Obtenida la mensura del área costanera y sus concesionarios "sería de conveniencia que por Decreto Supremo se pusiese a disposición del Ministerio de Fomento para radicación de pescadores de Dichato y Coliumo, los terrenos que fueran necesarios, en cuyo caso, esta oficina procedería a su división en sitios, distribuyéndolos entre los pescadores"22. Se entiende, por supuesto, que el mecanismo de adaptación es la utilización ante los tribunales de justicia y las instituciones de administración del Estado de las disposiciones del Código Civil que permitían el uso común de la franja litoral.

El 23 de agosto de 1934, el Capitán de Fragata y del Puerto de Talcahuano G. Silva se trasladó a Dichato con el objetivo de realizar las mediciones propuestas por el Director General de Pesca y Caza. En su informe planteó que "en la bahía de Coliumo existían dos sectores de playas ocupados por pescadores. Una parte de los pescadores, se encuentra en la parte de la playa que queda al sur de los Morros de Coliumo en la faja de playa de ocho metros de acuerdo con el art. 7 del Reglamento de Pesca. En esta parte hay situadas quince casas de pescadores y el suscrito midió en el terreno y dejó marcados los límites de la faja de ocho metros a que tienen derecho". En terreno había podido verificar que los pescadores reclamaban que los dueños del fundo los obligaban a arrendar una parte de la propiedad que colindaba con las casas de los pescadores y si estos no aceptaban "este temperamento les hacen presión para desalojarlos de sus casas, a que legalmente tienen derecho", agregando que "entre los reclamos que se presentaron figura uno que estimo mi deber dejar especial constancia y que tiene relación con el pescador Emeterio Urrutia a quien se le quemó su casa por orden del Sr. Carlos Merino, a quien le arrendaba el sitio. En vista de estos reclamos, el Capitán de Puerto "procedió a fijar los límites y notificar a los dueños de fundo que debían cesar en las continuas hostilidades que hacían objeto a los pescadores quedando de acuerdo en respetar los límites fijados como playa a que tienen derecho los pescadores ${ }^{23}$.

En 1939, para enfrentar e intentar solucionar el conflicto de intereses, por recomendación de la Dirección General de Tierras y Colonización, el gobierno presentó al Congreso Nacional un proyecto para expropiar una franja de terreno en el litoral de Dichato con el objetivo de radicar allí a los pescadores que por sus problemas con los propietarios y concesionarios se hallaban "instalados, en forma provisoria, en diversos parajes de nuestra caleta" ${ }^{\prime 2}$, ver Figura $\mathrm{N}^{\circ}$ 2. Los pescadores de la localidad se sintieron "verdaderamente halagados del marcado interés que el Supremo Gobierno demuestra por resolver el más viejo y fundamental de nuestros problemas, cual es el de

\footnotetext{
Archivo Nacional. Ministerio de Bienes Nacionales. Volumen 3258, 1948

Archivo Nacional. Ministerio de Bienes Nacionales. Volumen 3258, 1948

Archivo Nacional. Ministerio de Bienes Nacionales. Volumen 3258, 1948

Archivo Nacional. Ministerio de Bienes Nacionales. Volumen 3258, 1948
} 
nuestra radicación definitiva, lo que nos permitiría levantar casas cómodas e higiénicas, vivir en terreno propio y libres de molestias e inquietudes" 25 .

Figura $\mathrm{N}^{\circ} 2$

Plano de Ubicación de Pescadores

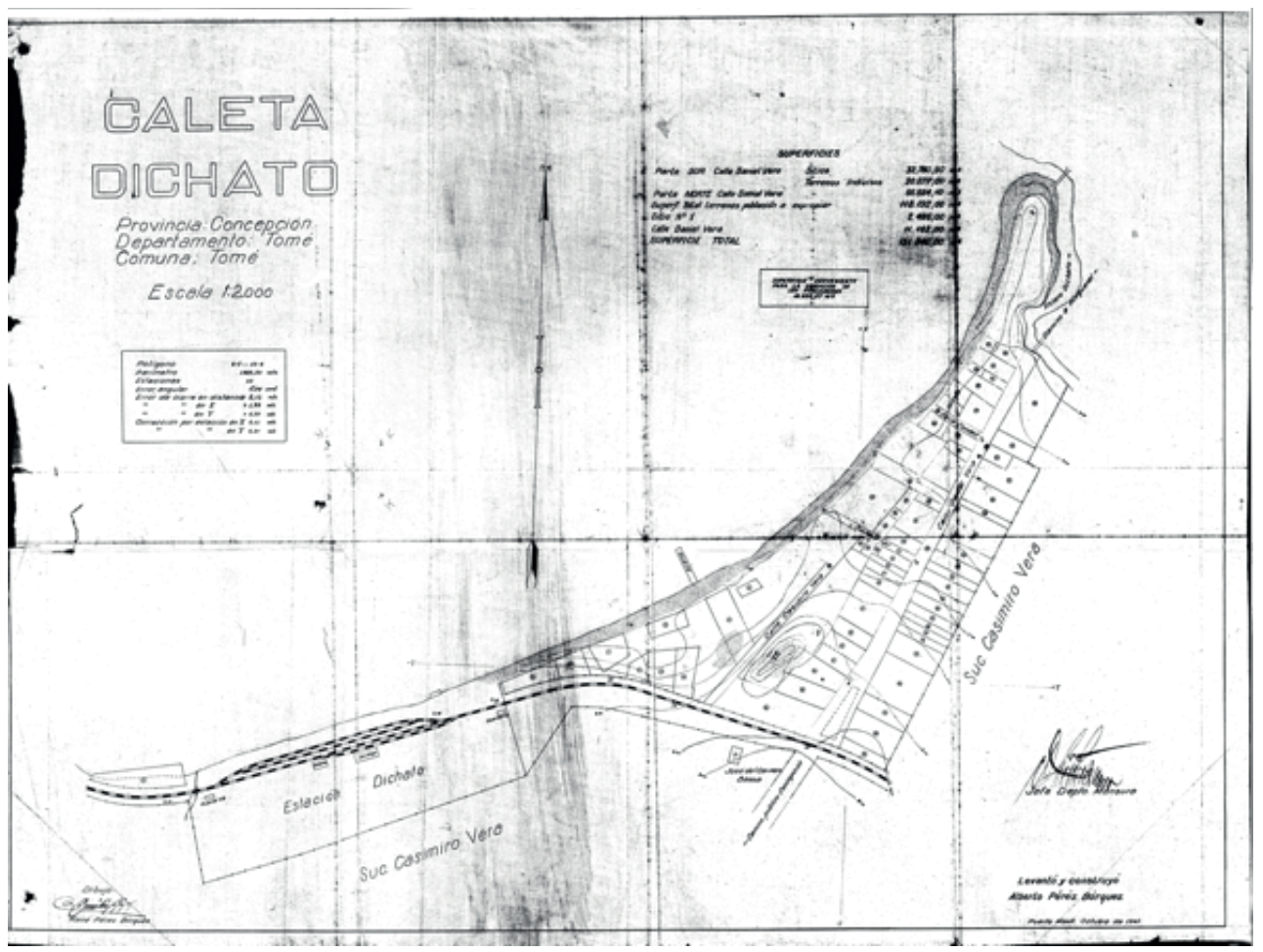

Fuente: Archivo Nacional. Ministerio de Bienes Nacionales. Volumen 3258, 1948.

No obstante, a juicio de los pescadores, "por desgracia los terrenos que se proyectan expropiar para radicarnos definitivamente no reúnen las condiciones naturales que son esenciales para nuestra industria. En efecto, esos terrenos compuestos en su totalidad de arenas de dunas, están abiertos al norte y no ofrecen abrigo alguno a nuestras embarcaciones durante el invierno y días de temporales, muy frecuentes en esta zona". Más adelante los pescadores indican que "afortunadamente" existían dentro de la misma bahía de Dichato "varios lugares especialmente apropiados para la radicación definitiva de nuestro gremio, que, a su ventajosa posición geográfica, une la no menos importante de su menor precio y mejor calidad". En esta circunstancias y "en virtud de estas buenas pero atendibles consideraciones venimos a suplicar a US., se sirva a disponer el retiro del proyecto de expropiación que el ejecutivo acaba de presentar al Congreso, a fin de que sea modificado en el sentido de que la expropiación se haga en el sector que mayores ventajas

25 Archivo Nacional. Ministerio de Bienes Nacionales. Volumen 3258, 1948. 
ofrezca para la industria pesquera, tomando a la vez el progreso del balneario, que no deseamos lesionar en forma alguna"26.

Cuando se inició la discusión del proyecto en la Cámara de Diputados los vecinos de Tomé también presentaron reparos al proyecto ${ }^{27}$ y los vecinos de Dichato se hicieron presentes en el Congreso con el objetivo de dificultar la tramitación de la iniciativa ${ }^{28}$. Por su parte, Nicolás Pardo, regidor de Tomé, asumiendo el conflicto por el uso de los bienes comunes del litoral de Dichato, denunciaba que

"con el disfraz de servir a las aspiraciones de los pescadores del lugar, lo que se persigue, en realidad, es amparar deleznables intereses particulares: se pretende regularizar, por medio de la expropiación la posesión ilegal de algunos sitios mantenida por don Amadeo León y otros. En efecto dentro de los terrenos cuya expropiación se propicia, el aludido Sr. León mantiene ilegalmente en su poder un sitio de 30 metros de frente por $80 \mathrm{~m}$. de fondo, en que tiene instalada una pequeña industria, relacionada con la pesca. Este sitio le fue dado por arrendamiento en virtud de una concesión fiscal obtenida por medio de antecedentes inexactos" 29 .

Asimismo, Armando Ordenes, entonces Intendente del Ñuble, indicaba que la posición que habían tomado los vecinos de las ciudades de Chillán y Bulnes era rechazar el proyecto enviado al Congreso Nacional ya que consideraban que la expropiación propuesta terminaría con "uno de los sitios de recreo predilectos de las familias modestas de la provincia y sus alrededores"30. En una carta del 18 de marzo de 1942 dirigida al vicepresidente de la República, los vecinos de Chillán afirmaban que el proyecto defendía intereses mezquinos causando un evidente y grave perjuicio a los intereses generales y permanentes del balneario de Dichato, que no sólo brindaba "excepcionales ventajas de todo orden al público general, y especialmente a los enfermos del corazón y del sistema nervioso sino que es ya un importante centro de atracción turística y veraniega, cuyo prestigio, cada día más sólido, ha llegado incluso al extranjero... cuenta actualmente con tres hoteles, valiosas residenciales veraniegas, varias casas de pensión y obras importantes de urbanización. Cuenta también con alumbrado eléctrico y hay posibilidad de que pronto sea dotado de agua potable". Indicaban asimismo que el gobierno de Pedro Aguirre Cerda había reconocido la importancia del balneario al disponer el levantamiento de un plano regulador que se hallaba en sus últimos trámites. Así, solicitaban al vicepresidente de la República que retirase "el susodicho proyecto de ley cuya aprobación en los términos que está concebido, importaría un verdadero golpe de muerte para el provenir de nuestra población". Por lo demás indicaban que la casi totalidad de los pescadores estaban "muy bien ubicados en diversos sectores de la bahía, dentro de la faja de ocho metros sobre la cual existe servidumbre legal a su favor". Así sobre la casi totalidad de los pescadores no existía, por tanto, ni podía "existir amenaza alguna", sin perjuicio de la "necesidad de propender a la radicación definitiva de todos los pescadores de la República, porque bien sabemos que ello constituye su más sentida aspiración ${ }^{311}$.

\footnotetext{
Archivo Nacional. Ministerio de Bienes Nacionales. Volumen 3258, 1948.

Cámara de Diputados, Sesión 8a. Extraordinaria. Lunes 18 de Noviembre de 1940, p.534.

Cámara de Diputados, Sesión 10ª. Extraordinaria. Martes 19 de Noviembre de 1940, p. 564.

Archivo Nacional. Ministerio de Bienes Nacionales. Volumen 3258, 1948

Archivo Nacional. Ministerio de Bienes Nacionales. Volumen 3258, 1948

Archivo Nacional. Ministerio de Bienes Nacionales. Volumen 3258, 1948
} 
Al día siguiente, el conflicto ocasionado por el proyecto de radicación de los pescadores escaló a la prensa. El 19 de marzo de 1942 el diario La Discusión de Chillán titulaba su editorial con la siguiente frase "Se ha producido consenso unánime para defender el balneario de Dichato y evitar su expropiación" (La Discusión, 1942: 7). En la misma edición el periódico publicó, además, un extenso artículo sobre el proyecto de expropiación en el cual el regidor Pardo indicaba que localmente "se había producido consenso unánime para defender el balneario de Dichato y evitar su expropiación" (La Discusión, 1942: 7). A su juicio a esta altura era claro que "la extensión de terreno que se quería expropiar comprendía el sector más valioso del radio urbano del balneario en el cual se encontraba ubicada la mayoría de la población y hacia la cual se estaba "extendiendo la edificación de hermosas residenciales veraniegas" (La Discusión, 1942: 7). En consecuencia, se intentaba "instalar al gremio de pescadores en el corazón mismo del balneario el que de hecho quedaría eliminado como tal y convertido en una simple caleta de pescadores, tal pretensión, en mi concepto, no solo es temeraria sino criminal, porque materializada significaría la muerte definitiva del balneario" (La Discusión, 1942: 7). Al mismo tiempo afirmaba que dentro de la misma bahía de Dichato existían "varios parajes que por su ubicación geográfica son excepcionalmente indicados para instalar una colonia pesquera como ser Coliumo y Los Morros donde actualmente se hallan instalados la casi totalidad de los pescadores y donde se ubicaron porque la naturaleza les brindaba allí indiscutibles ventajas" (La Discusión, 1942: 7).

Apoyando el sentir de sus vecinos, la Municipalidad de Chillán, por su parte, acordó por unanimidad pedir al supremo gobierno el retiro del proyecto de ley de expropiación de terrenos del balneario de Dichato por considerar que "lesionaba los intereses colectivos de la región al privarla del único lugar de solaz y veraneo para las clases modestas" 32 insinuando que la radicación de pescadores debía hacerse fuera de los límites urbanos del balneario, fijados por el Decreto Supremo No338 del 19 de enero de 1939.

Figura $\mathrm{N}^{\circ} 3$

Anteproyecto Plano de Urbanización de Dichato

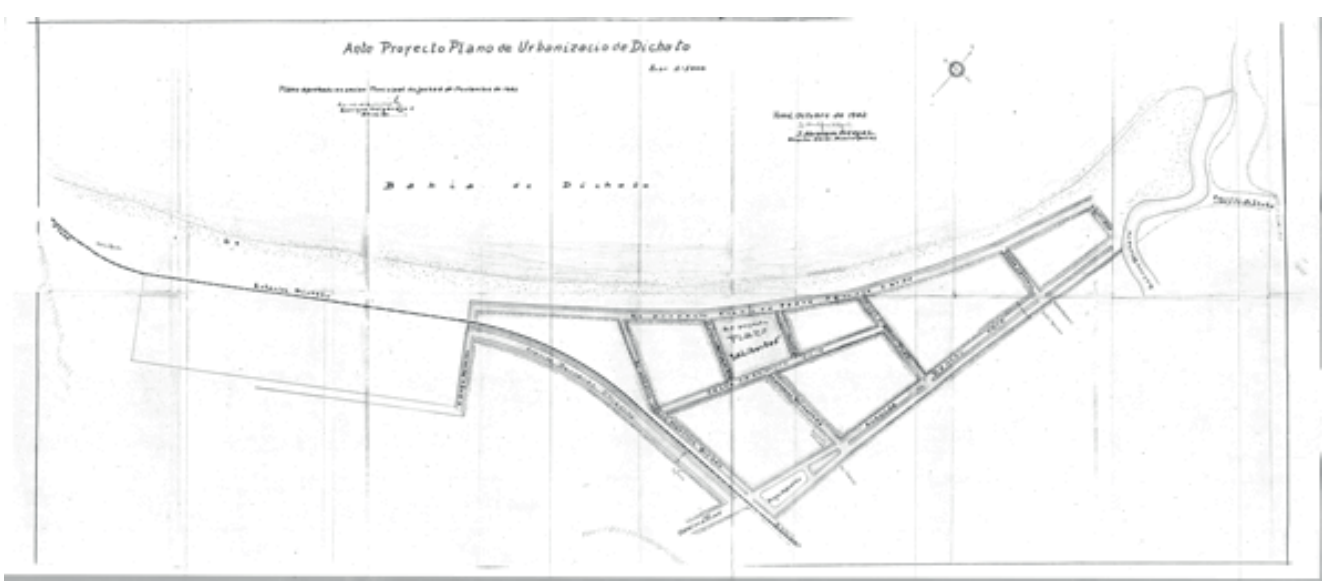

Fuente: Archivo Nacional. Ministerio de Bienes Nacionales. Volumen 3258, 1948.

32 Archivo Nacional. Ministerio de Bienes Nacionales. Volumen 3258, 1948. 
Dos años después, en 1944, ante la férrea oposición ciudadana, de las autoridades administrativas y comunales, y también de los propios pescadores, el Ministro de Tierras y Colonización devolvió el expediente a la Dirección General de Tierras y Colonización solicitando "un estudio más detenido del problema y que se investigara la actuación de los funcionarios de los empleados que tuvieron a cargo los estudios técnicos". En respuesta la dirección indicaba que no procedía aplicar medidas disciplinarias ya que la actuación de los funcionarios no había sido "influenciada por otros motivos que no fuera la conveniencia fiscal y del grupo de pescadores que habita en la caleta de Dichato, como también de las personas que van a ese balneario en busca de salud y de distracción". En relación al problema de la expropiación indicaba "que en la situación actual no sería oportuno dar a ese problema la solución señalada, pues tal medida sería resistida porfiadamente, como ya lo fue una vez por los particulares que han adquirido terrenos en el balneario de Dichato". La solución propuesta fue "expropiar únicamente la extensión que se destinará a formar la colonia de pescadores, con una cabida de 18.950,97 $\mathrm{mts}^{2 \prime}$, cifra significativamente inferior a los 78.191,27 $\mathrm{mts}^{2}$ planteados en el proyecto de expropiación anterior enviado al Congreso Nacional, véase Figura $\mathrm{N}^{\circ} 3$. Finalmente, tras varios años de conflicto, el 30 de marzo de 1948, aun no se habían concedido los fondos para la expropiación de los terrenos de Dichato por lo que la autoridades cerraron el proceso de expropiación aduciendo que no había por ahora "posibilidades de financiar dicha expropiación" ordenando, entonces, que se archivasen "estos antecedentes" 33 .

“Organizar el pasado en función del presente; eso es lo que podría denominarse función social de la historia" (Febvre, 1982: 245). Guiados por este llamado nos sentimos a la hora de ir cerrando nuestro análisis sobre la bahía de Dichato, si consideramos que desde el día posterior al terremoto y tsunamis desencadenados el 27 de febrero de 2010, el nivel de destrucción de la infraestructura costera afectó a seis regiones del país, siendo el sector de la pesca artesanal uno de los más afectados por el nivel de destrucción alcanzado (Contreras y Winckler, 2013). En estas circunstancias, vuelven a surgir conflictos entre propietarios, pescadores, y habitantes costeros por diferencias en el uso y propiedad de la franja litoral, esta vez con el Estado de Chile, gatillados por los procesos de reconstrucción promovidos por los diferentes organismos públicos. Considerando solo el proceso de reconstrucción de las viviendas destruidas en dicha franja, Riffo (2014) cuestiona "¿Cuáles son las razones por las cuales el campamento de emergencia "El Morro de Talcahuano" mantuvo su ubicación de origen, a diferencia de "El Molino de Dichato", relocalizado (hacia los cerros) luego del tsunami del 2010?" (Riffo, 2014: 10). No es gratuito que todos estos problemas vuelvan a resugir en tanto existe una relación directa con la casi nula participación de los habitantes localales en la solución de conflictos.

\section{Conclusiones}

La teoría de la tragedia de los bienes comunes ha centrado su atención en forma preferente en que al maximizar su propio beneficio cada comunero contribuía inevitablemente a la depredación y a la sobreexplotación de los recursos comunes y por ende del otro comunero, desencadenándose así una lucha encarnizada por obtener el máximo de beneficio en el corto plazo. A esta teoría se le ha reprochado que los denominados bienes comunes y los comuneros, en realidad, no se encontrarían exentos de mecanismos de regulación que incluso son creados por ellos mismos

33 Archivo Nacional. Ministerio de Bienes Nacionales. Volumen 3258, 1948 
pues evidentemente todos estarían interesados en explotar adecuadamente los recursos comunes. El problema, entonces, no es solamente el bien común en sí mismo y sus mecanismos de administración y gestión, sino que es, también, el de las relaciones que se establecen entre aquellos que con sus formas de vida lo reproducen diariamente y aquellos que intentan apropiarse de esa reproducción para su beneficio particular. En el caso estudiado, el conflicto entre propietarios, pescadores, habitantes costaneros, veraneantes y supuestos concesionarios fiscales por el uso de la franja litoral, ejemplifica e ilustra claramente como las disputas territoriales por los bienes comunes pueden llegar a lograr la generación de estrategias y mecanismos de adaptación que en su momento interrumpan los procesos globales de apropiación, cercamiento y destrucción de los bienes y espacios comunes.

No obstante, como señala Harvey (2004), más allá de los casos puntuales de autorregulación y de defensa ante el cercamiento, en términos generales, la usurpación y la reconversión de los bienes comunes en bienes privados finalmente ha terminado siendo clave como mecanismo para la absorción de los excedentes generados por el capital y el trabajo. En particular para el caso de las zonas costeras el turismo ha sido una actividad económica de usurpación y reconversión del borde costero en Latinoamérica. Los grandes proyectos de infraestructuras turísticas en las zonas costeras han desplazado a las comunidades de pescadores, además de los constantes intentos de convertirlos en mano de obra asalariada de estos complejos ${ }^{34}$, e.g. Lago Gigante, Nicaragua (Alvarado \& Taylor, 2014) y La Boquita, México (Doyon, 2002), en este sentido, mutatis mutandi, hay que destacar el papel jugado por el turismo en caso de la bahía de Dichato.

Por tanto, la lógica de la acumulación originaria, vista supra, no es exclusiva de las etapas iniciales del capitalismo sino inherente a él de ahí que Harvey propone renombrar este proceso como "desposeción" y nos llama a "una revisión general del rol permanente y de la persistencia de prácticas depredadoras de acumulación "primitiva" u "originaria" a lo largo de la geografía histórica de la acumulación de capital resulta muy pertinente" (Harvey, 2004: 112). Este tipo de acumulación por despojo del mar se da a lo largo del tiempo y en latitudes tan diversas como: India (Reeves et al., 2014), Canadá (Bernier, 1981), Estados Unidos (McEvoy, 1993), Indonesia (Bailey, 1988), Canarias (Pascual Fernández, 1999). Finalmente, llegados a este punto creemos que Chile puede ser incluido dentro de la lista de los casos de acumulación por despojo en su borde costero durante el siglo XX.

\section{Referencias bibliográficas}

AGUILERA, F. La tragedia de la propiedad común o la tragedia de la mala interpretación en economía. Agricultura y Sociedad, 1991, Nº 61, p. 157-183.

\footnotetext{
Mediante este proceso la calidad de vida de las comunidades se ve fuertemente perjudicada, entendiendo por calidad de vida la definición hecha por Haas (1999) como evaluación multidimensional de circunstancias individuales de vida en el contexto cultural y valórico al que se pertenece. Este perjuicio seria directamente producido por la desterritorializacion a la que se ven enfrentadas las comunidades. Por desterritorializacion nos referimos no solo el acto de desplazamiento de las comunidades sino también "la idea de movimiento y cambio tanto en relación a los seres humanos, como con referencia a bienes, símbolos e imaginarios" (Vilanova, 2009: 81). La idea ya trabajada por Marx en su percepción del capitalismo como un proceso como "una máquina devoradora, que paulatinamente se iba apropiando de diversos "territorios" -la agricultura, la cultura, la educación, la industria- hasta llegar a desterritorializarlos." (Vilanova, 2009: 81).
} 
ALBERT, F. El problema pesquero en Chile. Santiago de Chile: Cámara Chilena de la Construcción / Pontificia Universidad Católica de Chile, 2012.

ALEGRET, J. L. La antropología marina como campo de investigación de la antropología social. Agricultura y Sociedad, 1989, № 52, p. $119-142$.

ALVARADO, N. \& TAYLOR, M. ¿Del mar quien es dueño? Artisanal Fisheries, Tourism Development, and the Struggles over access to Marine Resources in Gigante, Nicaragua. Journal of Latin American Geography, 2014, Vol. 13, N³, p. 37-62.

ÁLVAREZ, E. Historia de la marina mercante chilena: 1541-2006. Valparaíso: Asociación Nacional de Armadores, 2006.

ARMADA DE CHILE. El poder naval chileno. Centenario Revista de Marina 1885-1985, dos tomos. Valparaíso: Revista Marítima, 1985.

BAILEY, C. The Political Economy of Marine Fisheries Development in Indonesia. Indonesia, 1988, Vol. 46, p. 25-28.

BARCA, S. Enclosing the River. Industrialisation and the 'Property Rights' Discourse in the Liri VaIley (South of Italy), 1806-1916. Environment and History, 2007, № 13, p. 3-23.

BERNIER, P. Pêche côtière, intervention de l'État et développement des forces productives à Rivière St-Paul. Anthropologie et Sociétés, 1981, Vol.5, No 1, p. 97-115.

BERRIOS, V. Recuerdo y olvido como parte de una historia: la ballenera de Quintay. Santiago de Chile: Tesis de Licenciatura, Universidad de Chile, 2011.

BOLSTER, J. Opportunities in Marine Environmental History. Environmental History, 2006, Vol. 3, No11, p. 567-597.

CARTES, A. Los cazadores de Mocha Dick: balleneros chilenos y norteamericanos al sur del Océano de Chile. Santiago de Chile: Pehuén, 2009.

CONTRERAS, M. \& WINCKLER, P. Pérdidas de vidas, viviendas, infraestructura y embarcaciones por el tsunami del 27 de Febrero de 2010 en la costa central de Chile. Obras y proyectos, 2013, $\mathrm{N}^{\circ}$ 14 , p. 6-19.

DIARIO LA DISCUSIÓN. Editorial Salvemos Dichato. Diario La Discusión, 19 de marzo de 1942.

DOYON, S. The Structural Marginalization of Artisanal Fishing Communities: The Case of La Boquita. Anthropologica, 2002, Vol. 44, No 1, p. 83-98.

DURRENBERGER, E.P \& PÁLSSON, G. Ownership at Sea: Fishing Territories and Access to Sea Resources. American Ethnologist, 1987, Vol. 14, № 3, p. 508-522. 
ELDEN, S. Thinking territory politically. Political Geography, 2010, Vol. 29, № 4, p. 238-241.

FEBVRE, L. Combates por la historia. Barcelona: Ariel, 1985.

FEENY, D.; BERKES, F.; MCCAY, B. \& ACHESON, J. Tragedy of the Commons: Twenty-Two Years Later. Human Ecology, 1990, No 18, p. 1-19.

FERNÁNDEZ, J.P. Antropología de la pesca en España, nuevas tendencias y nuevos problemas. Etnográfica, 1999, Vol. 3, № 2, p. 333-359.

GASCÓN, J. La polémica sobre la tragedia de los comunes: Un caso andino. Debate Agrario, 1996, $\mathrm{N}^{\circ} 25$, p. 21-28.

GONZÁLEZ DE MOLINA, M. De la "cuestión agraria" a la "cuestión ambiental" en la historia agraria de los noventa. Historia Agraria, 2000, N²2, p. 19-36.

GORDON, S. The economic theory of common property resource: the fishery. The Journal of Political Economy, 1954, Vol. 62, No 2, p. 124-142.

HAAS, B. Clarification and integration of similar quality of life concepts. Journal of nursing Scholarships, 1999, № 31, $215-220$.

HARDIN, G. La tragedia de los comunes. Gaceta Ecológica, 1995, №37, p. 38-48.

HARVEY, D. The new imperialism. Oxford: Oxford University Press, 2003.

HARVEY, D. El nuevo imperialismo: acumulación por desposesión. Socialist Register, 2004, Vol. 40, p. 99-129.

HASLETT, S. Costal Systems. New York: Routledge, 2009.

HERNÁNDEZ, J. A. Donde viven las ballenas: actividades balleneras en Isla Santa María y Chome del pionero Juan Macaya Aravena. Concepción: Editora Aníbal Pinto S.A, 2005.

KOLERS, A. Land, Conflict and Justice: A Political Theory of Territory. Cambridge: Cambrige University Press, 2009.

MANSFIELD, B. Neoliberalism in the oceans: 'rationalization, property rights, and the commons question. Geoforum, 2004a, №35, p. $313-326$.

MANSFIELD, B. Rules of Privatization: Contradictions in Neoliberal Regulation of North Pacific Fisheries. Annals of the Association of American Geographers, Vol. 94, № 3, 2004b, p. 565-584.

MANSFIELD, B. (editor). Privatization: Property and the Remaking of Nature-Society Relations. London: Blackwell, 2008. 
MARCH, H. Neoliberalismo y medio ambiente: una aproximación desde la geografía crítica. Documents d'Anàlisi Geogràfica, 2013, Vol. 59, № 1, p. 137-153.

MARX, K. El capital: Critica de la economía política. Santiago de Chile: LOM, 2010.

MCCARTHY, J. \& PRUDHAM, S. Neoliberal nature and the nature of neoliberalism. Geoforum, 2004, $N^{\circ} 35$, p. $275-283$.

MCCAY, B. \& JENTOFT, S. Market or community failure? Critical perspectives on common property research. Human Organization, 1998, Vol. 57, №1, p. 21-29.

MCEVOY, A. Historia y ecología de las pesquerías del nordeste del océano Pacífico. Ayer, 1993, Nº 11, p. 189-205.

MONSALVE, R. Industria Salmonera en Puerto Montt 1975 - 2007. Santiago de Chile: Tesis de Licenciatura, Universidad Alberto Hurtado, 2014.

NICHOLLS, N. La sociedad ballenera de Magallanes: de cazadores de ballenas a "héroes" que marcaron la soberanía nacional, 1906-1916. Historia, 2010, Vol. 1, № 43, p. 41-78.

OSTROM, E. Governing the Commons. Tthe Evolution of Institutions for Collective Action. Cambridge: Cambridge University Press, 1990.

PAYNE, B. Local Economic Stewards: The Historiography of the Fishermen's Role in Resource Conservation. Environmental History, 2013, Vol. 18, №1, p. 29-43.

REVISTA CATÓLICA. Estado de la industria pesquera en Chile. Revista Católica 294, 1913, №25, p. 741-744.

REEVES, P.; POKRANT, B. \& MCGUIRE, J. Changing Practice in the Madras Marine Fisheries: Legacies of the Fish Curing Yards. In: CHRISTENSEN, J \& TULL, M. (editors). Historical Perspectives of Fisheries Exploitation in the Indo-Pacific. Dordrecht: Springer, 2014, p. 41-62.

REPÚBLICA DE CHILE. Código civil de la República de Chile. Santiago de Chile: Imprenta Nacional, 1856.

REPÚBLICA DE CHILE. Diario Oficial de la República de Chile, Nº14.344, 5 noviembre de 1925. Santiago de Chile: Imprenta Nacional, 1925.

RIFFO, C. Conflicto y disputa por una construcción alternativa del territorio. Borde costero de la provincia de Concepción post tsunami 2010. Santiago de Chile: Tesis de Magister, Universidad Católica, 2014.

ROSENBERG, M.J. Evolución urbana de Caleta Chome y la influencia de la industria ballenera. Concepción: Tesis de Licenciatura, Universidad de Concepción, 2011. 
SALAZAR, G. Historia de la acumulación capitalista en Chile. Santiago de Chile: LOM, 2012.

SEVILLA-BUITRAGO, A. Territory and the governmentalisation of social reproduction: parliamentary enclosure and spatial rationalities in the transition from feudalism to capitalism. Journal of Historical Geography, 2012, Vol. 38, N³, p. 209-219.

SCOTT, A. The Fishery: The Objectives of Sole Ownership. Journal of Political Economy, 1955, Vol. $63, N^{\circ} 2$, p. 116-124.

SMOUT, T.C. Garrett Hardin. The Tragedy of the Commons and the Firth of Forth. Environment and History, 2011, No 17, p. 357-378.

THIBERGE, C. En vingt ans, la Terre a perdu un dixième de ses espaces sauvages. Paris: Diario Le Monde, 2016.

THOMPSON, E.P. Costumbres en común. Barcelona: Critica, 1995.

URIBE, L. Nuestra Marina Mercante 1810-1904: reseña histórica. Valparaíso: Talleres Tipografía de la Armada, 1904.

VARGAS, J.F. Historial del mar de Chile: algunos siniestros marítimos acaecidos en el siglo XX. Valparaíso: Imprenta y Litografía Soto, 2000.

VÁZQUEZ DE ACUÑA, I. Historia naval del Reino de Chile 1520-1826. Valparaíso: Compañía Sudamericana de Vapores, 2004.

VELIZ, C. Historia de la Marina Mercante de Chile. Santiago de Chile: Editorial Universitaria, 1961.

VILANOVA, N. Desterritorialización. En: SZURMUK, M. \& MCKEE IRWIN, R. (coordinadores). Diccionario de estudios culturales latinoamericanos. México: Siglo XXI, 2009, p. 80-84.

YOUNG, E. State Intervention and Abuse of the Commons: Fisheries Development in Baja California Sur, México. Annals of the Association of American Geographers, 2011, Vol. 91, № 2, p. 283-306.

WARDLE, A. El vapor conquista el Pacífico: anales de las hazañas marítimas 1840-1940. Valparaíso: Imprenta y Litografía Universo, 1940. 